\title{
Esophageal capsule endoscopy is not the optimal technique to determine the need for primary prophylaxis in patients with cirrhosis
}

\author{
Karen L. Krok ${ }^{1}$, Rebecca Rankin Wagennar ${ }^{2}$, Sergey V. Kantsevoy ${ }^{3}$, Paul J. Thuluvath ${ }^{3,4}$
}

\author{
${ }^{1}$ Division of Gastroenterology, Hershey Medical Center, Hershey, Pennsylvania, USA \\ ${ }^{2}$ Division of Gastroenterology and Hepatology, Johns Hopkins University School \\ of Medicine, Baltimore, Maryland, USA \\ ${ }^{3}$ Institute for Digestive Health and Liver Disease, Mercy Medical Center, Baltimore, \\ Maryland, USA \\ ${ }^{4}$ University of Maryland School of Medicine, Baltimore, USA
}

Submitted: 25 October 2014

Accepted: 27 November 2014

Arch Med Sci 2016; 12, 2: 365-371

DOI: 10.5114/aoms.2016.59263

Copyright $\odot 2016$ Termedia \& Banach

\begin{abstract}
Introduction: Capsule endoscopy has been suggested as a potential alternative to endoscopy for detection of esophagogastric varices and severe portal hypertensive gastropathy ( $\mathrm{PHG}$ ). The aim of the study was to determine whether PillCam esophageal capsule endoscopy could replace endoscopy for screening purposes.

Material and methods: Sixty-two patients with cirrhosis with no previous variceal bleeding had PillCam capsule endoscopy and video endoscopy performed on the same day. Sensitivity, specificity, and positive and negative predictive values (PPV, NPV) of capsule endoscopy were compared to endoscopy for the presence and severity of esophageal and gastric varices, PHG and the need for primary prophylaxis. Patients' preference was assessed by a questionnaire.

Results: Four (6\%) patients were unable to swallow the capsule. Sensitivity, specificity, PPV and NPV of capsule endoscopy for detecting any esophageal varices $(92 \%, 50 \%, 92 \%, 50 \%)$, large varices $(55 \%, 91 \%, 75 \%, 80 \%)$, variceal red signs (58\%, 87\%, 69\%, 80\%), PHG (95\%, 50\%, 95\%, 50\%), and the need for primary prophylaxis $(91 \%, 57 \%, 78 \%, 80 \%)$ were not optimal, with only moderate agreement ( $\kappa$ ) between capsule and upper GI endoscopy. Had only a capsule endoscopy been performed, 12 (21.4\%) patients would have received inappropriate treatment. Capsule endoscopy also failed to detect $(0 / 13)$ gastric varices. The majority of patients ranked capsule endoscopy as more convenient (69\%) and their preferred (61\%) method.

Conclusions: Despite the preference expressed by patients for capsule endoscopy, we believe that upper GI endoscopy should remain the preferred screening method for primary prophylaxis.
\end{abstract}

Key words: capsule endoscopy, esophageal varices.

\section{Introduction}

The presence of gastroesophageal varices is not universal in patients with cirrhosis. In cross-sectional studies, gastroesophageal varices are found in only $30-50 \%$ of patients with cirrhosis [1-3]. The current evidence suggests that a third of patients with documented esophageal

\author{
Corresponding author: \\ Paul J. Thuluvath MD, FRCP \\ Center for Liver \\ and Biliary Diseases \\ Institute for Digestive Health \\ and Liver Disease \\ Mercy Medical Center \\ 301 St. Paul Place \\ Baltimore, MD 21202-2165 \\ E-mail: thuluvath@gmail.com
}


varices bleed within 2 years from the time of diagnosis, with an associated mortality of $20-40 \%$ with each bleeding episode [2, 4-7]. The in-hospital mortality of acute variceal bleeding has remained around $20 \%$ in the past decade despite the advances in the management of this complication [8]. The objective of primary prophylaxis is to reduce the first bleeding episode in high-risk patients with minimal costs and complications [9]. There is overwhelming evidence to suggest that primary prophylaxis with non-selective $\beta$-blockers is beneficial in patients with cirrhosis and large varices with stigmata of imminent bleeding. In addition to the presence of large esophageal varices or those with red signs, the presence of severe portal hypertensive gastropathy $(\mathrm{PHG})$ and large gastric varices may also benefit from primary prophylaxis with non-selective $\beta$-blockers.

Endoscopic screening of high-risk subjects is the gold standard for screening, but it is not routinely performed in the majority of patients with advanced cirrhosis. Fewer than $50 \%$ of patients referred for liver transplant evaluation have been screened for the presence of esophageal varices [10]. Markov modeling studies have suggested that universal upper $\mathrm{Gl}$ endoscopic screening is very expensive, and therefore screening is recommended only for high-risk subjects [11, 12]. Even in high-risk subjects, the limiting factors for a screening strategy are patient compliance and the costs (procedure-related expenses and the lost revenues for the patient and an accompanying person) associated with upper gastrointestinal (GI) endoscopy. Recently, capsule (PillCam ESO) endoscopy has been used in screening for esophageal varices [13-18]. The potential benefits of screening patients with PillCam ESO capsule endoscopy include convenience, tolerability, lack of sedation, and the ability of physicians or their extenders to screen patients in out-patient clinics. If found to be equally reliable as upper GI endoscopy, in selecting patients who need primary prophylaxis, capsule endoscopy may reduce costs and increase compliance.

The objective of this comparative study was to determine whether capsule endoscopy could be used reliably to select patients who would benefit from primary prophylaxis of bleeding from esophageal or gastric varices and PHG. We also wanted to assess the patients' preference between standard upper Gl endoscopy and capsule endoscopy.

\section{Material and methods}

\section{Patients}

We prospectively studied patients with advanced cirrhosis who were undergoing screening for esophageal varices. The diagnosis of cirrhosis was based on a combination of clinical, laboratory, imaging or histological factors. Criteria for inclusion were as follows: (1) advanced cirrhosis with portal hypertension based on imaging or clinical suspicion; (2) age greater than or equal to 18 years; (3) able to give informed consent. Criteria for exclusion were as follows: (1) current implantable cardioverter-defibrillator or pacemaker; (2) suspected intestinal obstruction; (3) esophageal swallowing disorder or Zenker's diverticulum; (4) esophageal stenosis; (5) pregnancy; and (6) previous endoscopic or surgical treatment or TIPS.

\section{Methods}

\section{Esophageal capsule endoscopy}

After an overnight fast, patients underwent capsule endoscopy with the Inscope PillCam ESO video capsule, an ingestible esophageal capsule that is $11 \times 26 \mathrm{~mm}$ in size, that detects images from both ends of the capsule at a rate of 14 images per second. We followed the protocol as recommended by the capsule manufacturers. The three sensor arrays were placed strategically on the patient's chest and connected to a data recorder that was placed on the bed next to the patient. Patients then drank $60 \mathrm{ml}$ of water with 20 drops of simethicone. Patients were positioned flat on the bed with their head on a pillow. The capsule was ingested with their head flat on the bed with a minimal amount of water. The patients remained supine for $5 \mathrm{~min}$ and thereafter the bed was raised by $30^{\circ}$ angles every 2 min until the patient was upright. Images were captured for $20 \mathrm{~min}$ and without drinking or eating until the procedure ended.

\section{Standard video upper GI endoscopy}

After ingestion and completion of the $20 \mathrm{~min}$ recordings of the capsule endoscopy, a video upper Gl endoscopy was performed on the same day. A combination of midazolam and fentanyl was used for sedation. The endoscopy was video recorded for later review as needed. During the course of the endoscopy, a complete evaluation of the stomach and duodenum was performed and the presence and severity of portal hypertensive gastropathy as well as gastric varices were noted. Gastric varices were described by the location (cardia or fundus) and the size (small and large). The PHG also was noted and graded (absent, mild or severe). The mosaic appearance of the gastric mucosa with and without red spots was graded as severe and mild PHG, respectively. Grading of esophageal varices was completed in the following standardized manner. After examination of the stomach, the stomach was deflated and the endoscope was withdrawn to the gastro-esophageal junction, and this level was marked based on the 
centimeter markings on the side of the endoscope. Air was then inflated in the distal esophagus and the varices were graded using a standard grading scale, the modified Japanese Research Society for Portal Hypertension classification for grading varices $[19,20]$. In this classification, esophageal varices are described by the extent (distance from GE junction in $\mathrm{cm}$ ), size (FO - no varices, F1 - small and non-tortuous, F2 - tortuous, but less than $50 \%$ radius, $\mathrm{F} 3$ - large and tortuous), color (blue or white), and presence of red signs (red wale markings, cherry red spots, hematocystic spots).

\section{Evaluation of capsule endoscopy examination}

The capsule endoscopy images were graded independently in a blinded fashion by an independent and experienced investigator (PJT). Although the Japanese Research Society for Portal Hypertension classification for staging varices is not applicable for capsule endoscopy, we adopted the same numerical grading by modifying it for capsule picture frames. In this system, we used FO when no varices were seen on any frames, F1 when any signs of small varix were seen, and F2 and F3 when the largest varix occupied less than $25 \%$ and more than $25 \%$ of the circumference of the capsule frame respectively. The frames were played forward and backwards multiple times in slow motion before a final score was assigned. The upper $\mathrm{Gl}$ endoscopic image grading of the varices was then compared to the grading of the varices as seen on the capsule endoscopy in a blinded fashion. To determine the need for primary prophylaxis of esophageal varices, we combined F2 and F3 (large varices \pm red signs), and to determine the need for overall prophylaxis, we considered all those with large esophageal varices, red signs, large gastric varices or severe PHG as potentially eligible.

\section{Patient satisfaction assessment}

At the end of both procedures, patient acceptance was assessed by a 5-question survey (Table I) that the patients completed and returned within a week after completing the procedures.

\section{Ethics}

The study was approved by the institutional review board at the Johns Hopkins School of Medicine (reference number NA_00002592). Written consent was obtained from all patients prior to enrollment in the study.

\section{Statistical analysis}

Statistical analysis was performed to assess sensitivity, specificity and accuracy of capsule en- doscopy versus upper Gl endoscopy in determining the need for prophylaxis or treatment. A weighted $\kappa$ scale was used to determine agreement of variceal grade by capsule endoscopy compared to upper Gl endoscopy, using upper Gl endoscopy as the gold standard. Results are expressed as frequency and percentage as appropriate. Cases with missing data for any particular measurement were omitted from analyses involving that measurement. The data analysis was generated using SAS software, version 9.1.3 of the SAS System for Windows (copyright 2007 SAS Institute Inc).

\section{Results}

A total of 70 consecutive patients with cirrhosis who presented for routine screening of esophageal varices were screened for the study (Figure 1). Of these, 62 (male $=35)$ patients were then enrolled in the study. Six patients were excluded from the final analysis; 4 patients were unable to swallow the capsule and 2 capsule recordings were lost. Fifty-six patients were available for the final anal-

Table I. Patient satisfaction questionnaire

I. What is your overall satisfaction with the CAPSULE
ENDOSCOPY?
1. Excellent.
2. Very good.
3. Good.
4. Fair.
5. Poor.
II. What is your overall satisfaction with the UPPER
ENDOSCOPY?
1. Excellent.
2. Very good.
3. Good.
4. Fair.
5. Poor.

III. How would you compare the level of discomfort for the procedures?

1. CAPSULE ENDOSCOPY was more uncomfortable than UPPER ENDOSCOPY.

2. They were equally uncomfortable.

3. UPPER ENDOSCOPY was more uncomfortable than CAPSULE ENDOSCOPY.

4. I am not sure.

IV. Which procedure was more convenient?

1. CAPSULE ENDOSCOPY was more convenient than UPPER ENDOSCOPY.

2. They were equally convenient.

3. UPPER ENDOSCOPY was more convenient than CAPSULE ENDOSCOPY.

4. I am not sure.

V. If you required a procedure every 2 years, which procedure would you prefer?

1. I prefer CAPSULE ENDOSCOPY over UPPER ENDOSCOPY.

2. I have no preference.

3. I prefer UPPER ENDOSCOPY over CAPSULE ENDOSCOPY.

4. I would never have either procedure again. 


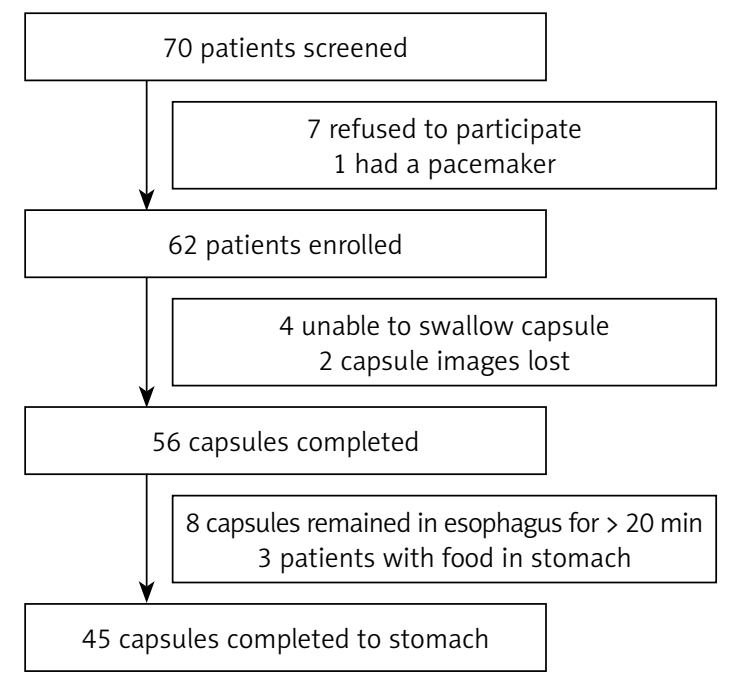

Figure 1. Enrollment flow sheet ysis; of these 21 patients had ascites and mean body mass index was 28.3 (range: 16.9-44.1).

The average esophageal transit time was $7 \mathrm{~min}$ and 11 s (range: 6 to 1200 s). Four capsules were still present in the esophagus at the time of the upper Gl endoscopy, which was at least $30 \mathrm{~min}$ after swallowing the capsule, and 4 capsules just entered the stomach at 20 min when the capsule stopped recording, precluding the ability to analyze the stomach. Three patients had food in their stomach at the time of the capsule endoscopy, precluding an accurate evaluation of portal hypertensive gastropathy and gastric varices. There were no retained capsules in this study population.

Eight (14\%) patients had no esophageal varices, $48(86 \%)$ patients had varices (14 patients had small varices (F1) and 34 had large varices (F2, F3)) on upper Gl endoscopy; 19 (34\%) patients

Table II. Grading of esophageal varices

\begin{tabular}{|c|c|c|c|c|c|}
\hline \multirow{2}{*}{$\begin{array}{l}\text { Capsule endoscopy - } \\
\text { esophageal varices grade }\end{array}$} & \multicolumn{4}{|c|}{ Upper endoscopy - esophageal varices grade } & \multirow[t]{2}{*}{ Total } \\
\hline & Fo & F1 & F2 & F3 & \\
\hline FO & 4 & 4 & 0 & 0 & 8 \\
\hline F1 & 1 & 3 & 3 & 0 & 7 \\
\hline F2 & 3 & 7 & 11 & 8 & 29 \\
\hline F3 & 0 & 0 & 3 & 9 & 12 \\
\hline Total & 8 & 14 & 17 & 17 & 56 \\
\hline
\end{tabular}

Analysis of all grades of esophageal varices using the modified Japanese Research Society for Portal Hypertension classification; $\kappa=0.47$, sensitivity $=92 \%$, specificity $=50 \%, P P V=92 \%, N P V=50 \%$.

Table III. Grading of esophageal varices based on the need for prophylaxis

\begin{tabular}{|lccc|}
\hline $\begin{array}{l}\text { Capsule endoscopy } \\
\text { - esophageal varices } \\
\text { grade }\end{array}$ & $\begin{array}{l}\text { Upper endoscopy - } \\
\text { esophageal varices }\end{array}$ & Total \\
\cline { 2 - 3 } & \multicolumn{3}{c|}{ grade } \\
\hline F0-F1 & F2-F3 & \\
\hline F2-F3 & 12 & 3 & 15 \\
\hline Total & 10 & 31 & 41 \\
\hline
\end{tabular}

Separate analysis of grading of esophageal varices as large and not large; $\kappa=0.48$, sensitivity $=55 \%$, specificity $=91 \%, P P V=75 \%$, $N P V=80 \%$.
Table IV. Presence of red signs (red wale markings, hematocystic spots and cherry red spots) on esophageal varices as noted by the upper endoscopy and capsule endoscopy

\begin{tabular}{|c|c|c|c|}
\hline \multirow[t]{2}{*}{$\begin{array}{l}\text { Capsule endoscopy } \\
\text { - red signs }\end{array}$} & \multicolumn{2}{|c|}{$\begin{array}{l}\text { Upper endoscopy - } \\
\text { red signs }\end{array}$} & \multirow[t]{2}{*}{ Total } \\
\hline & Present & Absent & \\
\hline Present & 11 & 5 & 16 \\
\hline Absent & 8 & 32 & 40 \\
\hline Total & 19 & 37 & 56 \\
\hline
\end{tabular}

Table V. Sensitivity, specificity, PPV and NPV of capsule endoscopy using upper GI endoscopy as the gold standard

\begin{tabular}{|lcccc|}
\hline Variable & Sensitivity (\%) & Specificity (\%) & PPV (\%) & NPV (\%) \\
\hline Detection of any varices & 92 & 50 & 92 & 50 \\
\hline Detection of large varices & 55 & 91 & 75 & 80 \\
\hline Presence of red signs & 57.9 & 86.5 & 68.8 & 80 \\
\hline Presence of PHG & 95 & 50 & 95.1 & 50 \\
\hline Detection of severe PHG & 85 & 33 & 74 & 50 \\
\hline Need for primary prophylaxis & 91.4 & 57.1 & 78 & 80 \\
\hline
\end{tabular}


had red signs on the varices. The PHG (73\%) was present in 41 patients, and it was severe in 27 patients. Thirteen (23\%) patients had gastric varices.

Tables II-V show the correlation between the esophageal capsule and upper $\mathrm{Gl}$ endoscopy in grading esophageal varices. As judged by upper Gl endoscopy, varices were absent or small (FO-F1) in $22(39 \%)$ patients and large (F2-F3) in 34 (61\%) patients (Tables II and III). As judged by capsule endoscopy, varices were absent or small (FO-F1) in $15(27 \%)$ patients and large (F2-F3) in 41 (73\%) patients. The level of agreement was moderate as measured by the $\kappa$ statistic of 0.48 . There were 4 instances when varices were seen on upper endoscopy but were graded as FO on capsule endoscopy; all of these varices were graded as F1 on the upper Gl endoscopy. In 3 patients the capsule endoscopy graded varices as F1 but on upper Gl endoscopy these varices were actually F2. The capsule endoscopy never failed to detect F3 varices and only downstaged varices from F2/F3 to F0/F1 in 3 cases.

Table IV shows the correlation between the capsule and upper GI endoscopy in noting red signs (red wale markings, hematocystic spots and cherry red spots), which are markers for an increased risk of bleeding. As judged by upper GI endoscopy, 19 (34\%) patients had red signs present, of which the capsule endoscopy only noted 11 cases. There were false positives in $5(9 \%)$ patients on capsule endoscopy. The level of agreement measured by the $\kappa$ statistic was 0.47 , which is considered moderate agreement.

Although capsule endoscopy had a very high sensitivity (92\%) for detecting any varices, the specificity was very low (50\%) (Table V). In contrast, sensitivity was very poor (55\%) and specificity was high (91\%) for selecting patients with large varices for primary prophylaxis; similar results were also seen with the presence of red signs.

The capsule endoscopy did not show gastric varices in any of the 13 patients who were found to have gastric varices on upper endoscopy. In one of the 13 patients with gastric varices there was a significant amount of food in the stomach, precluding an adequate evaluation of the gastric mucosa; the remaining 12 capsules passed into a debris-free stomach and still failed to note gastric varices.

Tables VI and VII shows the correlation between the capsule and upper Gl endoscopy in noting and grading PHG. The PHG could be commented on in only 45 of the 56 capsules; in 8 cases the capsule either barely or never entered the stomach by the end of the recording, and in 3 cases there was food and debris in the stomach, precluding an adequate examination of the stomach. In those 45 patients, the capsule endoscopy had excellent sensitivity (95.1\%) and PPV (95.1\%) for noting the presence of PHG (Table VI). The level of agreement measured by the $\kappa$ statistic was 0.45 , which is considered moderate agreement. The level of agreement measured by the $\kappa$ statistic was only 0.20 , which is considered slight agreement, for assessing the severity of the PHG (Table VII). Four patients with severe PHG would not have received primary prophylaxis as they were downgraded by the capsule endoscopy.

\section{Capsule endoscopy for identification of patients who required primary prophylaxis}

Table VIII shows the correlation between the recommendations for primary prophylaxis based on the images from the capsule endoscopy versus the upper Gl endoscopy. In total, 35 (62.5\%) patients were offered primary prophylaxis based on the upper GI endoscopy. Forty-one (73.2\%) patients would have been offered prophylaxis based

Table VI. Presence of PHG detected by upper GI endoscopy and capsule endoscopy

\begin{tabular}{|c|c|c|c|}
\hline \multirow[t]{2}{*}{$\begin{array}{l}\text { Capsule endoscopy - } \\
\text { portal hypertensive } \\
\text { gastropathy }\end{array}$} & \multicolumn{2}{|c|}{$\begin{array}{c}\text { Upper endoscopy - } \\
\text { portal hypertensive } \\
\text { gastropathy }\end{array}$} & \multirow[t]{2}{*}{ Total } \\
\hline & Present & Absent & \\
\hline Present & 39 & 2 & 41 \\
\hline Absent & 2 & 2 & 4 \\
\hline Total & 41 & 4 & 45 \\
\hline
\end{tabular}

Table VII. Grading of PHG using upper GI endoscopy and capsule endoscopy

\begin{tabular}{|c|c|c|c|}
\hline \multirow[t]{2}{*}{$\begin{array}{l}\text { Capsule endoscopy - } \\
\text { portal hypertensive } \\
\text { gastropathy grade }\end{array}$} & \multicolumn{2}{|c|}{$\begin{array}{l}\text { Upper endoscopy - } \\
\text { portal hypertensive } \\
\text { gastropathy grade }\end{array}$} & \multirow[t]{2}{*}{ Total } \\
\hline & Mild & Severe & \\
\hline Mild & 4 & 4 & 8 \\
\hline Severe & 8 & 23 & 31 \\
\hline Total & 12 & 27 & 39 \\
\hline
\end{tabular}

$\kappa=0.2$, sensitivity $85 \%$, specificity $33 \%, P P V=74 \%, N P V=50 \%$.

Table VIII. Comparison of recommendations for $\beta$-blocker prophylaxis between images seen on capsule endoscopy versus upper endoscopy

\begin{tabular}{|lccc|}
\hline Capsule endoscopy & \multicolumn{2}{c}{ Upper endoscopy } & Total \\
\cline { 2 - 3 } & $\begin{array}{c}\text { Recom- } \\
\text { mended }\end{array}$ & $\begin{array}{c}\text { Not } \\
\text { recom- } \\
\text { mended }\end{array}$ & \\
\hline Recommended & 32 & 9 & 41 \\
\hline Not recommended & 3 & 12 & 15 \\
\hline Total & 35 & 21 & 56 \\
\hline
\end{tabular}

$\kappa=0.52$, sensitivity $=91.4 \%$, specificity $=57.1 \%, P P V=78 \%$, $N P V=80 \%$. 
Table IX. Response to patient satisfaction questionnaire

\begin{tabular}{|c|c|}
\hline Question & $\begin{array}{l}\text { Patient response } \\
\qquad N=56 \\
\text { Average (median) } \\
\text { Total }{ }^{\#}(\%)\end{array}$ \\
\hline $\begin{array}{l}\text { Overall satisfaction with capsule } \\
\text { endoscopy: }\end{array}$ & $1.86(1)$ \\
\hline Excellent & $29(52)$ \\
\hline Very good & $14(25)$ \\
\hline Good & $8(14)$ \\
\hline Fair & $1(2)$ \\
\hline Poor & $4(7)$ \\
\hline $\begin{array}{l}\text { Overall satisfaction with video } \\
\text { endoscopy: }\end{array}$ & $2.09(2)$ \\
\hline Excellent & $23(41)$ \\
\hline Very good & $13(23)$ \\
\hline Good & $15(27)$ \\
\hline Fair & $2(4)$ \\
\hline Poor & $3(5)$ \\
\hline Level of discomfort comparison: & $2.38(2)$ \\
\hline Capsule > upper endoscopy & $14(25)$ \\
\hline Capsule = upper endoscopy & $16(29)$ \\
\hline Capsule < upper endoscopy & $30(17)$ \\
\hline Not sure & $16(9)$ \\
\hline Convenience of procedure: & $1.45(1)$ \\
\hline Capsule > upper endoscopy & $39(69)$ \\
\hline Capsule = upper endoscopy & $10(18)$ \\
\hline Capsule < upper endoscopy & $6(11)$ \\
\hline Not sure & $1(2)$ \\
\hline Preference of procedure: & $1.57(1)$ \\
\hline Capsule > upper endoscopy & $34(61)$ \\
\hline Capsule = upper endoscopy & $12(21)$ \\
\hline Capsule < upper endoscopy & $10(18)$ \\
\hline Not sure & $0(0)$ \\
\hline
\end{tabular}

on the capsule endoscopy images. The capsule endoscopy had a sensitivity of $91.4 \%$, specificity of $57.1 \%$, PPV of $78.0 \%$ and NPV of $80.0 \%$ for predicting the need for prophylactic $\beta$-blocker therapy. The level of agreement between these two methods was only moderate $(\kappa=0.51)$. Had only a capsule endoscopy been done, $12(21.4 \%)$ patients would have received inappropriate treatment; 3 patients would not have received primary prophylaxis, and 9 patients would have received unnecessary treatment.

\section{Patient satisfaction assessment}

Fifty-six patients completed and returned their patient satisfaction questionnaires. All patient surveys that were returned were included in this analysis, including the 4 patients who could not swallow the capsule and the 2 patients whose capsule videos were lost. The results of this questionnaire are shown in Table IX. In general the trend was for an increase in satisfaction with the capsule endoscopy over the upper endoscopy; $52 \%$ of patients ranked their capsule endoscopy satisfaction as excellent, and only $41 \%$ ranked their upper endoscopy satisfaction as excellent. Capsule endoscopy was ranked as more convenient than upper Gl endoscopy by $69 \%$ of patients, and $61 \%$ of patients would prefer a surveillance program that used capsule endoscopy over upper Gl endoscopy.

\section{Discussion}

In this study, the capsule endoscopy was well tolerated, and the majority of patients thought capsule endoscopy was more convenient and preferred it over upper endoscopy. These findings may suggest that patients are more likely to comply with a screening program that involves capsule endoscopy. Capsule endoscopy, however, had a low specificity for detecting varices that required primary prophylaxis. Capsule endoscopy also failed to detect gastric varices and failed to provide adequate information regarding the presence and severity of PHG.

Currently, primary prophylaxis with non-selective $\beta$-blockers is recommended for large esophageal varices (F2 or greater), varices with red wale signs, severe PHG and large gastric varices. There was only moderate agreement between the video upper Gl endoscopy and the capsule endoscopy in determining the need for primary prophylaxis. Had only a capsule endoscopy been performed, $12(21.4 \%)$ patients would have received inappropriate treatment; 3 patients would not have received primary prophylaxis, and 9 patients would have received unnecessary therapy. The capsule endoscopy had a low specificity (57.1\%) for deciding the need for primary prophylaxis. The failure of capsule endoscopy to detect gastric varices did not make a difference in this study only because of the excellent agreement between esophageal and gastric varices in all 13 patients with gastric varices.

How does our study compare with the previous 6 studies (excluding those presented in an abstract form)? In the largest study to date, de Franchis et al. reported a sensitivity of $84 \%$ and specificity of $88 \%$ for detecting varices; corresponding values for varices that required treatment were $78 \%$ and $96 \%$ respectively [17]. Other studies have reported a wide range of sensitivity (68-100\% for detection, $63-78 \%$ for treatment) and specificity $(67-100 \%$ for detection, $82-96 \%$ for treatment) for the detection or the treatment of esophageal varices [13-18]. We had a low sensitivity for detecting large varices (55\%) and red 
signs (57.9\%). The high sensitivity and relatively low specificity for primary prophylaxis of esophageal varices suggest that capsule endoscopy, in its current form, is not optimal for this purpose.

There are many explanations for the poor performance of capsule endoscopy. The transit time of the capsule through the esophagus was very variable. In 23 (39\%) patients, the transit time was extremely rapid (less than $2 \mathrm{~min}$ ), and this precluded a thorough evaluation of the esophageal mucosa. In 8 patients, because of the slow transit time, the capsule did not enter or just entered the stomach in 20 min precluding an evaluation of PHG. Even when the capsule entered the stomach, its ability to assess the presence of gastric varices was extremely poor (0/13); similar observations were made in another study, where only 1 of 8 gastric varices was detected by capsule endoscopy [18]. Although understandable (inability to direct, lack of air insufflation and the presence of gastric contents), inability to detect gastric varices is another disadvantage of capsule endoscopy. In addition, in our study, 4 patients (4/62) could not swallow the capsule in the dorsal decubitus position even after repeated attempts. One of the limitations of this study is the relatively small sample size, but we do not believe a larger sample size would change these results significantly.

What about cost advantages with capsule endoscopy? Markov models have previously been used to attempt to assess the cost benefits and showed a possible benefit with capsule endoscopy. Any future study should include the costs associated with technical failures, inappropriate treatment and the bleeding risks associated with inappropriate treatment.

In conclusion, our results suggest that capsule endoscopy is well tolerated and safe, and is preferred by patients over standard video upper Gl endoscopy for screening for varices and gastropathy. Capsule endoscopy, however, in its current technological state, is not the optimal tool for selection of patients for primary prophylaxis.

\section{Conflict of interest}

Karen L. Krok was a recipient of the AASLD Advanced Hepatology Fellowship. This was an investigator initiated study, and the Inscope PillCam ESO used in the study was donated by Ethicon Endo-Surgery, Inc. (Johnson \& Johnson).

\section{References}

1. Bosch J, Garcia-Pagan JC. Complications of cirrhosis. 1. Portal hypertension. J Hepatol 2000; 32 (1 Suppl): 141-56.

2. Gores GJ, Wiesner RH, Dickson ER, et al. A prospective evaluation of esophageal varices in primary biliary cirrhosis: development, natural history, and influence on survival. Gastroenterology 1989; 96: 1552-9.
3. Zaman A, Becker T, Lapidus J, et al. Risk factors for the presence of varices in cirrhotic patients without a history of variceal hemorrhage. Arch Int Med 2001; 161: 2564-70.

4. Merigan TC, Plotkin GR, Davidson CS. Effect of intravenously administered posterior pituitary extract on hemorrhage from bleeding esophageal varices. N Engl J Med 1962; 266: 134-5.

5. Conn HO, Ramsby GR, Storer EH, et al. Intraarterial vasopressin in the treatment of upper gastrointestinal hemorrhage: a prospective controlled clinical trial. Gastroenterology 1975; 68: 211-21.

6. Fogel RM, Knauer MC, Andres LL, et al. Continuous intravenous vasopressin in active upper gastrointestinal bleeding. A placebo controlled trial. Ann Intern Med 1982; 96: 565-9.

7. Pugh RNH, Murray-Lyon IM, Dawson JL, et al. Transection of the oesophagus for bleeding oesophageal varices. Br J Surg 1973; 60: 646-9.

8. Dy SM, Cromwell DM, Thuluvath PJ, et al. Hospital experience and outcomes for esophageal variceal bleeding. Int J Qual Health Care 2003; 15: 139-46.

9. Thuluvath PJ, Krishnan A. Primary prophylaxis of variceal bleeding. Gastrointest Endosc 2003; 58: 558-67.

10. Arguedas MR, McGuire BM, Fallon MB, et al. The use of screening and preventive therapies for gastroesophageal varices in patients referred for evaluation of orthotopic liver transplantation. Am J Gastroenterol 2001; 96: 833-7.

11. Spiegel BM, Targownik L, Dulai GS, et al. Endoscopic screening for esophageal varices in cirrhosis: is it ever cost effective? Hepatology 2003; 37: 366-77.

12. Saab S, DeRosa V, Nieto J, et al. Costs and clinical outcomes of primary prophylaxis of variceal bleeding in patients with hepatic cirrhosis: a decision analytic model. Am J Gastroenterol 2003; 98: 763-70.

13. Eisen GM, Eliakim R, Zaman A, et al. The accuracy of PillCam ESO Capsule endoscopy versus conventional upper endoscopy for the diagnosis of esophageal varies: a prospective three-center pilot study. Endoscopy 2006; 38: 31-5.

14. Lapalus MG, Dumortier J, Fumex F, et al. Esophageal capsule endoscopy versus esophagogastroduodenoscopy for evaluating portal hypertension: a prospective comparative study of performance and tolerance. Endoscopy 2006; 38: 36-41.

15. Frenette CT, Kuldau JG, Hillebrand DJ, et al. Comparison of esophageal capsule endoscopy and esophagogastroduodenoscopy for diagnosis of esophageal varices. World J Gastroenterol 2008; 14: 4480-5.

16. Pena LR, Cox T, Koch AG, et al. Study comparing oesophageal capsule endoscopy versus EGD in the detection of varices. Dig Liv Dis 2008; 40: 216-23.

17. de Franchis R, Eisen GM, Laine L, et al. Esophageal capsule endoscopy for screening and surveillance of esophageal varices in patients with portal hypertension. Hepatology 2008; 47: 1595-603.

18. Lapalus MG, Soussan EB, Gaudric M, et al. Esophageal capsule endoscopy vs. EGD for the evaluation of portal hypertension: a French prospective multicenter comparative study. Am J Gastroenterol 2009; 104: 1112-8.

19. Beppu K, Inokuchi K, Koyanagi N, et al. Prediction of variceal hemorrhage by esophageal endoscopy. Gastrointest Endosc 1981; 27: 213-8.

20. Idezuki Y. General rules for recording endoscopic findings of esophagogastric varices (1991). Japanese Society for Portal Hypertension. World J Surg 1995; 19: 420-2. 